\title{
Efektivitas Iklan dalam Menumbuhkan Brand Awareness SMA Sampoerna
}

\author{
The Effectiveness of Advertisement In Gaining Brand Awareness of Sampoerna High School
}

\author{
Fahrizal Sukma ${ }^{*}$, Ma'mun Sarma², dan Muhammad Syamsun ${ }^{3}$
}

\author{
1Penjaminan Infrastruktur Indonesia (Persero) \\ Handphone 08111100786, Email: fahrizal.sukma@gmail.com \\ ${ }^{2}$ Departemen Manajemen, Fakultas Ekonomi Manajemen Institut Pertanian Bogor \\ Jl. Kamper, Kampus IPB Dramaga Bogor 16680; Hp. 0811110016, Email: mamun_sarma@yahoo.com \\ ${ }^{3}$ Departemen Manajemen, Fakultas Ekonomi Manajemen Institut Pertanian Bogor \\ Jl. Kamper, Kampus IPB Dramaga Bogor 16680; Hp. 08128544286
}

\begin{abstract}
ABSTRAK
Agar dapat bersaing dengan sekolah-sekolah lainnya, SMA Sampoerna melaksanakan program periklanan pada media cetak dan media elektronik. Selain untuk memperkenalkan program SMA Sampoerna, periklanan dilakukan untuk meningkatkan kesadaran merek dimata masyarakat. Tujuan utama penelitian ini menganalisis faktor-faktor yang memengaruhi efektivitas iklan dalam meningkatkan kesadaran merek SMA Sampoerna. Berdasarkan penelitian terdahulu dan kajian pustaka yang dilakukan bahwa efektifitas iklan dipengaruhi oleh mutu endorser, ketepatan pemilihan media periklanan dan daya tarik pesan iklan. Selanjutanya efektifitas periklanan dapat meningkatkan brand awareness dimata khalayak umum. Responden penelitian ini adalah orang tua siswa SMA Sampoerna yang berdomisili di Jakarta, Bogor, Tangerang, Bekasi (Jabotabek). Pengumpulan data dilakukan menggunakan metode sensus pada bulan Juli-Oktober 2014 kepada 80 orang tua siswa. Data yang terkumpul diolah menggunakan Structural Equation Model (SEM). Hasil analisis SEM menunjukkan daya tarik pesan iklan memiliki pengaruh nyata terhadap efektifitas iklan SMA Sampoerna dan efektifitas iklan SMA Sampoerna berpengaruh nyata terhadap peningkatan kesadaran merek SMA Sampoerna. Selain itu, ketepatan pemilihan media juga memiliki pengaruh nyata terhadap peningkatan kesadaran merek SMA Sampoerna. Berdasarkan hasil analisis tersebut, agar dapat meningkatkan efektifitas program iklan sehingga meningkatkan brand awareness SMA Sampoerna dimata khalayak maka pendekatan yang dapat dilakukan adalah berfokus pada peningkatan daya tarik pesan perikalanan.
\end{abstract}

Kata kunci: brand awareness, efektifitas iklan, SMA Sampoerna

\section{ABSTRACT}

To compete with other schools, Sampoerna High School has been implementing advertisement programs in printed and electronic media. Moreover, advertisement programs that have been implementing are to increase brand awareness in public. The main aim of this research is to analyze factors that influencing. Previous researches and literatures review show that advertisement's effectiveness is effected by the endorser's quality, the appropriate selecting of advertisement media and the attractiveness of advertisement's message. Then the advertisement's effectiveness enhances the brand awareness. The respondents are the parents of Sampoerna High School's students who live in Jakarta, Bogor, Tangerang, and Bekasi (Jabotabek). The data collected by a cencus to 80 parents on July to October 2014. The data that collected has processed using Structural Equation Model (SEM). The result of SEM analysis indicates that the attractiveness of advertisement's message has significant effect to effectiveness of advertisement, and advertisement's effectiveness shows significant effect to brand awareness' enhancement. Moreover, the appropriate selecting of advertisement media also shows significant effect to

Korespondensi:

*) Sampoerna Strategic Square, Tower Utara lantai 14, Jalan Jenderal Sudirman Kav. 45 Jakarta 12930, Indonesia. Telp +6221 579 50550, Fax +6221 57950040, Email: s.fahrizal@iigf.co.id 
brand awareness. Based on the results, in order to have an effective advertisement in gaining brand awareness of Sampoerna High School, the approach of the advertisement campaign should be focusing on enhancement of the attractiveness advertisement's message.

Key words: advertising effectiveness, brand awareness, Sampoerna High School

\section{PENDAHULUAN}

Peraturan Pemerintah nomor 17 tahun 2010 menjelaskan bahwa pengelolaan dan penyelenggaraan pendidikan di Indonesia dapat dilakukan oleh pemerintah, satuan atau program pendidikan dan penyelenggaraan satuan pendidikan yang didirikan masyarakat atau swasta (Dikti, 2010). Dalam memperkenalkan sekolah dan program pendidikannya kepada masyarakat penyelenggara pendidikan, khususnya swasta perlu melakukan promosi melalui program periklanan. Media tradisional seperti televisi, radio, koran, majalah dan papan reklame merupakan bentuk umum yang digunakan untuk mengirimkan pesan iklan kepada konsumen (Lamb et al, 2001).

Salah satu keuntungan utama dari iklan adalah kemampuannya mengkomunikasikan kepada sejumlah besar orang dalam suatu waktu, namun demikian, iklan mungkin juga hanya menjangkau target yang sempit dari sejumlah calon konsumen. Hal ini membuat keputusan pemilihan media yang dilakukan oleh pemasar berperan dalam menentukan keberhasilan iklan yang telah dipasang. Iklan meskipun tidak secara langsung berakibat terhadap pembelian, juga iklan merupakan sarana untuk membantu pemasaran yang efektif untuk menjalin komunikasi antara perusahaan dengan konsumen dalam usahanya menghadapi pesaing dan meningkatkan brand awareness. Strategi periklanan juga berhubungan erat dengan proses komunikasi dan pembuatan pesan.

Proses kamunikasi dan pesan yang menarik saja tidak cukup untuk membuat iklan efektif, diperlukan endorser yang membantu pengiklan untuk mencitrakan produknya dimata masyarakat. Riyanto (2008) dalam penelitiannya Analisis Faktor Yang mempengaruhi Efektifitas Iklan dan Implikasinya Terhadap Sikap Merek Pada Studi Kasus Pada Iklan Ponds, menyimpul-kan bahwa suatu iklan agar dapat efektif harus memiliki daya tarik yang tinggi, harus kreatif dan juga didukung dengan menggunakan endorser yang memiliki kredibilitas tinggi

Puspitasari (2009) dalam penelitiannya Faktor-Faktor Yang Mempengaruhi Efektivitas Iklan Dalam Menumbuhkan Brand Awareness,
Studi Kasus Pada Program Periklanan Telkom Flexi menemukan bahwa untuk dapat menghasilkan sebuah iklan yang memiliki efektifitas yang tinggi sehingga dapat meningkatkan brand awareness, dilakukan dengan pendekatan tiga buah peubah, yaitu dengan memperhatikan endorser yang digunakan dalam iklan, memperhatikan pesan yang akan disampaikan dalam iklan apakah bersifat informatif atau mengajak konsumen dan dengan memperhatikan media yang digunakan untuk beriklan.

Berdasarkan riset dari lembaga riset pemasaran CM (2012) pada 14 sekolah swasta nasional dan internasional di Jabotabek, bahwa pada tahun 2008-2011, terjadi trend positif kenaikan pengeluaran iklan pada sekolah swasta di Jabotabek, yaitu rataan 20\% tiap tahunnya. Sembilan puluh dua persen pengeluaran iklan tersebut adalah pengeluaran iklan koran. SMA Sampoerna yang dulu dikenal Sampoerna Academy yaitu sekolah berasrama yang berdiri tahun 2011 atas inisiatif Putra Sampoerna Foundation (PSF) dan berlokasi di Bogor. Menurut survei yang dilakukan oleh Nielsen (2012) di Jabotabek dan 4 kota besar di Indonesia (Surabaya, Medan, Balikpapan dan Makassar) SMA Sampoerna menduduki peringkat ke-4 dalam hal kesadaran merek (top of mind). Karena itu, SMA Sampoerna menjalankan program periklanan untuk meningkatkan awareness dimasyarakat, khususnya wilayah Jakarta dan sekitarnya (Jabotabek).

Program periklanan yang dilakukan oleh SMA Sampoerna mencapai lebih dari 50\% biaya promosi (2,3 milyar rupiah) pada periode 2012 hingga Maret 2014. Mayoritas pengeluaran berupa pengeluaran iklan koran dan majalah. Pada tahun kedua pengeluaran iklan tersebut meningkat besar dan diprediksikan terus meningkat setiap tahunnya. Koran Seputar Indonesia dan Koran Kompas adalah koran harian yang paling sering digunakan. Radio Cosmopolitan FM adalah stasiun radio yang paling banyak digunakan untuk program radio talkshow.

Dengan bervariasinya program iklan dan media yang digunakan oleh SMA Sampoerna serta belum dilakukannya evaluasi pengaruh program iklan terhadap brand awareness SMA Sampoerna, maka dari sudut pandang perusaha- 
an dan peneliti, perlu adanya suatu penelitian tehadap efektivitas program iklan dan kaitannya terhadap peningkatan brand awareness SMA Sampoerna di masa sekarang ini.

Tujuan dilakukannya penelitian ini: (1) menganalisis pengaruh endorser terhadap efektifitas iklan SMA Sampoerna, (2) menganalisis pengaruh pesan iklan terhadap efektivitas iklan SMA Sampoerna, (3) menganalisis pengaruh pemilihan media periklanan terhadap efektivitas iklan SMA Sampoerna, dan (4) menganalisis pengaruh efektivitas iklan SMA Sampoerna terhadap brand awareness SMA Sampoerna.

Kebaruan dari penelitian ini adalah pengembangan sebuah teori/metode pengukuran efektivitas periklanan terhadap peningkatan brand awareness ke dalam bidang baru yaitu pendidikan. Seperti yang dijelaskan pada penelitian-penelitian terdahulu di atas, bahwa teori/metode pengukuran yang berkembang saat ini menitikberatkan pada produk-produk konsumsi/ritel. Dengan adanya penelitian ini diharapkan dapat menjadi salah satu alternatif metode pengukuran efektifitas periklanan pada bidang pendidikan khususnya adalah sekolah menengah atas berasrama.

Uniknya pada sektor pendidikan dimana khalayak/orang tua siswa tidak terlalu gampang untuk berpindah merek (sekolah) sehingga diperlukan suatu konsep periklanan yang dapat mempersuasi khalayak/orang tua siswa. Pada umumnya berdasarkan penelitian-penelitian terdahulu dan teori-teori yang disampaikan para pakar pemasaran, periklanan dan perilaku pelanggan bahwa suatu iklan yang efektif dipengaruhi oleh tiga hal yaitu mutu endorser, ketepatan pemilihan media periklanan dan daya tarik pesan periklanan. Harapannya metode pengukuran ini dapat direplikasi kepada penelitian sejenis di area atau subjek sekolah berasarama lainnya.

\section{METODE PENELITIAN}

Kerangka pemikiran adalah model konseptual tentang bagaimana teori berhubungan dengan berbagai faktor yang telah diidentifikasi sebagai masalah riset (Umar, 2003). Penelitian ini tidak menghubungkan efektivitas iklan terhadap sikap dan perilaku pembelian, melainkan terhadap kesadaran terhadap merek. Pada produk baru, program iklan berfokus meningkatkan kesadaran khalayak terhadap merek. Khususnya pada bidang pendidikan, menjadi top of mind merek tidak mudah, karena khalayak sudah mempunyai referensi produk yang kuat dan susah untuk berpindah merek.

Visi dan misi perusahaan dituangkan dalam program kerja perusahaan tahunan. Program kerja disusun dengan memperhatikan masukan dari donatur dan untuk mempromosikan program kerja dilakukan program promosi yang termasuk di dalamnya adalah program periklanan. Efektivitas program periklanan tersebut dicerminkan oleh tiga faktor yaitu endorser, pesan iklan dan media iklan. Efektifitas iklan diprediksi mempengaruhi peningkatan brand awareness. Hasil evaluasi terhadap faktor yang mempengaruhi efektifitas iklan dan peningkatan brand awareness menjadi masukan bagi program periklanan dimasa datang. Kerangka pemikiran penelitian seperti tersaji pada Gambar 1.

Penelitian dilakukan selama empat bulan, yaitu bulan Juli hingga Oktober 2014 dengan responden adalah orang tua siswa SMA Sampoerna yang berdomisili di wilayah Jakarta, Bogor, Tangerang dan Bekasi (Jabotabek).

\section{Perumusan Hipotesa}

Hipotesa menurut Umar (2003) berfungsi sebagai pegangan atau jawaban sementara penelitian yang masih perlu diuji kebenarannya. Selain itu hipotesa juga berfungsi sebagai penunjuk arah penyelidikan lebih lanjut, terutama sebagai sebuah konsep yang diharapkan terus berkembang dan sebagai bahan dari bangunan suatu teori.

Uji hipotesis antara peubah pada masingmasing hipotesis pada nilai $\mathrm{p}$-value $<0,05$ yang menghasilkan nilai $t$ hitung $>t$ tabel $(1,96)$ maka Ha diterima dan tolak H0. Perumusan hipotesa sebagai berikut:

1. Hipotesis pertama: Mutu endorser berpengaruh pada efektifitas iklan.

$\mathrm{H}_{\mathrm{a}}$ : Mutu endorser berpengaruh pada efektifitas iklan.

Ho: Mutu endorser tidak berpengaruh pada efektifitas iklan.

2. Hipotesis kedua: Daya tarik pesan iklan berpengaruh pada efektifitas iklan.

$\mathrm{H}_{\mathrm{a}}$ : Daya tarik pesan iklan berpengaruh pada efektifitas iklan.

Ho: Daya tarik pesan iklan tidak berpengaruh pada efektifitas iklan. 


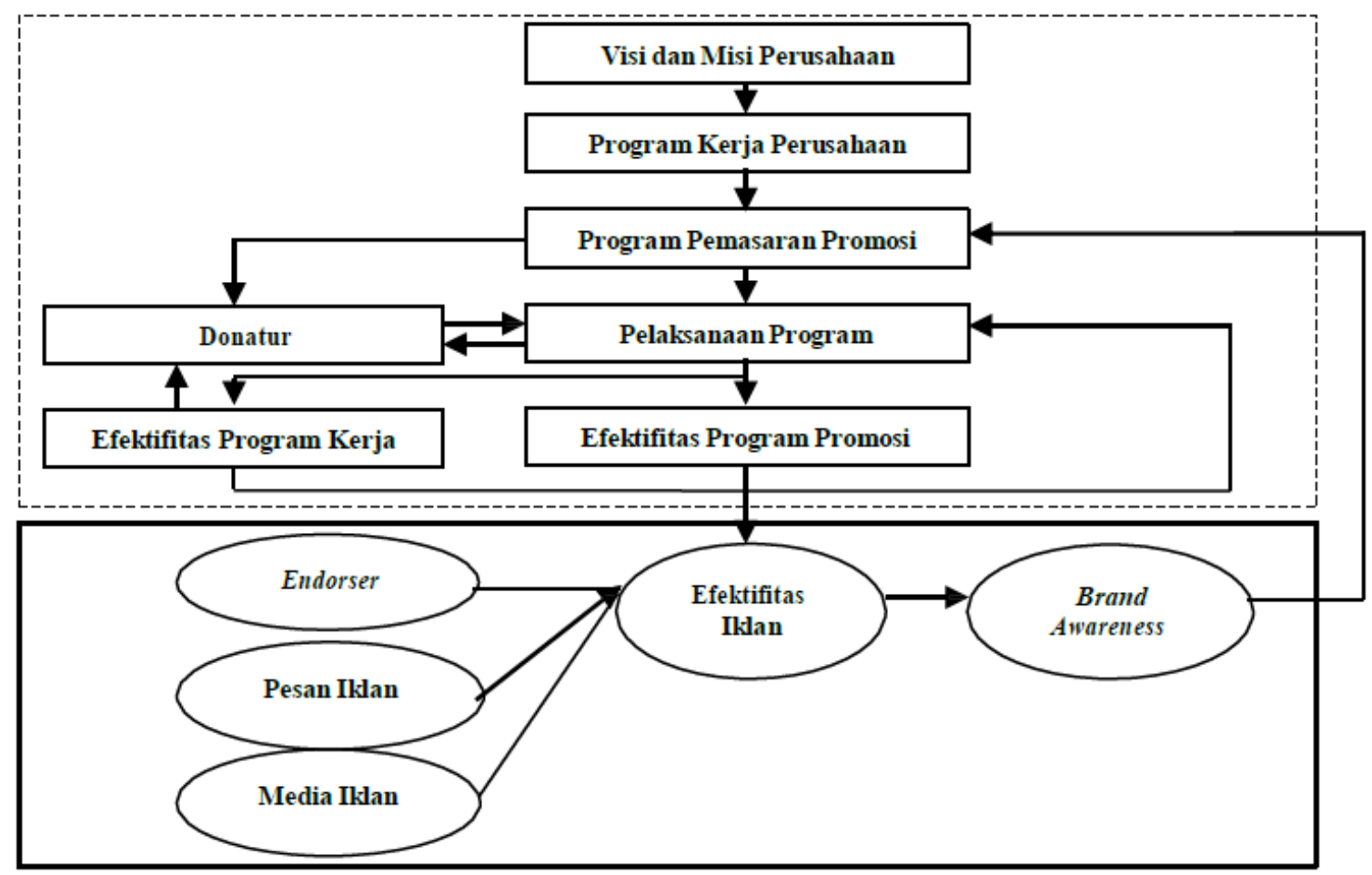

Gambar 1. Kerangka pemikiran penelitian

3. Hipotesis ketiga: Ketepatan pemilihan media iklan berpengaruh pada efektifitas iklan.

$\mathrm{H}_{\mathrm{a}}$ Ketepatan pemilihan media iklan berpengaruh pada efektivitas iklan

$\mathrm{H}_{0}$ : Ketepatan pemilihan media iklan tidak berpengaruh pada efekvifitas iklan

4. Hipotesis keempat: Efektivitas iklan berpengaruh terhadap brand awareness produk.

$\mathrm{H}_{\mathrm{a}}$ : Efektivitas iklan berpengaruh terhadap brand awareness produk.

$\mathrm{H}_{0}$ : Efektivitas iklan tidak berpengaruh terhadap brand awareness produk.

\section{Peubah dan Indikator Penelitian}

Kotler dan Keller (2009) menjelaskan bahwa inti dari pemasaran (marketing) adalah mengidentifikasi dan memenuhi kebutuhan manusia dan sosial. Tugas pemasar adalah merencanakan aktivitas-aktivitas pemasaran dan membentuk program pemasaran yang terintegrasi penuh. Periklanan adalah salah satu program promosi dari pemasar kepada calon pembeli, namun iklan juga digunakan untuk menciptakan, mengkomunikasikan dan menyampaikan nilai-nilai untuk mempengaruhi perilaku target audien (Kotler dan Lee, 2009).

Berdasarkan kajian pustaka dan hipotesis yang diajukan dalam penelitian ini, berikut adalah peubah dan indikator penelitian. Berdasarkan Kotler dan Kussdyarsana dalam Puspitasari (2009), Sumarwan (2011) dan Sasetyo (2012), peubah endorser dicerminkan oleh indikator kecocokan endorser dengan khalayak ( $\left.\mathrm{G}_{1}\right)$, kecocokan endorser dengan merek $\left(\mathrm{G}_{2}\right)$, daya tarik endorser $\left(\mathrm{G}_{3}\right)$ dan keyakinan terhadap simbol jaminan standar $\left(\mathrm{G}_{4}\right)$.

Peubah daya tarik pesan iklan dicerminkan oleh indikator pesan iklan menarik perhatian (attention) $\left(\mathrm{H}_{5}\right)$, pesan iklan menarik minat (interest) $\left(\mathrm{H}_{6}\right)$, pesan iklan membangkitkan keinginan (desire) $\left(\mathrm{H}_{7}\right)$ dan pesan iklan menyebabkan tindakan (action) $\left(\mathrm{H}_{8}\right)$ (Kotler dan Kennedy dalam Puspitasari (2009).

Menurut Lee dalam Puspitasari (2009), Lamb et al (2001) peubah pemilihan media iklan dicerminkan oleh indikator mutu siaran ( $(9)$, popularitas media $\left(\mathrm{I}_{10}\right)$, penjadwalan iklan $\left(\mathrm{I}_{11}\right)$, jangkauan media $\left(\mathrm{I}_{12}\right)$ dan frekuensi iklan $\left(\mathrm{I}_{13}\right)$. Peubah efektifitas iklan menurut Schutls dan Tannebaum, Percy dan Rositer dalam Puspitasari (2009) dan Lamb et al (2001) dicerminkan oleh indikator merek dikenal dan diingat $\left(\mathrm{J}_{14}\right)$, khalayak memahami keunggulan (J15), khalayak memiliki kepercayaan (J16), khalayak meyakini produk lebih baik $\left(\mathrm{J}_{17}\right)$, memengaruhi pembelian/ penggunaan $\left(\mathrm{J}_{18}\right)$ dan membuat citra positif terhadap produk $\left(\mathrm{J}_{19}\right)$. Sedangkan peubah brand awareness menurut Rangkuti dalam Puspitasari (2009) dicerminkan oleh indikator ketidaksadaran merek (unware of brand) (K20), pengenalan merek (brand recognition) $\left(\mathrm{K}_{21}\right)$, ingat terhadap merek (brand recall) $\left(\mathrm{K}_{22}\right)$ dan merek menjadi pilihan utama (top of mind) $\left(\mathrm{K}_{23}\right)$. 


\section{Pengumpulan Data}

Jenis data yang diperlukan dalam penelitian ini adalah data primer dan sekunder. Data primer diperoleh dengan wawancara terstruktur menggunakan kuesioner dan wawancara mendalam kepada beberapa responden. Data sekunder diperoleh dari internet, studi kepustakaan dan penelitian terdahulu yang relevan, bertujuan untuk memperdalam pembahasan penelitian ini.

Data dikumpulkan melalui kuesioner dengan pertanyan bersifat tertutup. Skala yang digunakan 1-10 untuk memperoleh data bersifat interval, tanggapan paling positif (sangat setuju) diberi nilai paling besar dan tanggapan paling negatif (sangat tidak setuju) diberi nilai paling kecil. Pemilihan skala tersebut dimaksudkan untuk mendapatkan jawaban akurat dari responden dan untuk menghindari jawaban yang nertral atau tidak tahu.

Jumlah populasi siswa SMA Sampoerna yang berasal dari Jabotabek adalah 80 orang yang berasal dari kelas 10, 11 dan 12, sehingga sensus ini akan dilakukan kepada 80 orang tua siswa/ wali yang putra/putrinya bersekolah di SMA Sampoerna. Jumlah responden pada masingmasing kota tersaji pada Tabel 1.

Tabel 1. Jumlah responden penelitian

\begin{tabular}{lc}
\hline $\begin{array}{c}\text { Kota Asal } \\
\text { Responden }\end{array}$ & $\begin{array}{c}\text { Target Responden } \\
\text { (orang) }\end{array}$ \\
\hline Jakarta & 31 \\
Bogor & 22 \\
Tangerang & 19 \\
Bekasi & 8 \\
\hline Total & 80 \\
\hline
\end{tabular}

Peneliti meminta tanggapan dari responden, yaitu 80 orang tua murid/wali yang berasal dari Jabotabek dan sudah pernah menyaksikan/ mendengar program iklan SMA Sampoerna melalui media elektronik (talkshow radio) dan atau media cetak (iklan koran). Metode sensus digunakan untuk mendapatkan gambaran yang menyeluruh dari orang tua siswa yang berasal dari Jabotabek terhadap program iklan SMA Sampoerna. Batas waktu pengumpulan kuesioner tersebut adalah tanggal 31 Oktober 2014 dan sampai dengan batas waktu pengumpulan tersebut kuesioner yang terkumpul sejumlah 69 eksemplar.

\section{Pengolahan dan Analisis Data}

Data yang telah terkumpul diolah menggunakan metode analisis Structural Equation Model (SEM). Dalam penelitian ini digunakan metode SEM berbasis variance atau component based, karena dengan metode ini tidak memerlukan banyak asumsi pada data yang diolah. Data diolah dengan software Microsoft Excel 2010 dan SmartPLS. Peneliti dibantu oleh seorang assisten untuk pengolahan data pada penelitian ini.

\section{HASIL DAN PEMBAHASAN}

Jumlah kuesioner yang dikembalikan sebanyak 69 eksemplar atau $86 \%$ dari total responden, dan 11 kuesioner lainnya tidak terkumpul karena: (1) tiga responden tidak mengembalikan kuesioner akibat putra/putri telah mengundurkan diri dari SMA Sampoerna, dan (2) delapan responden tidak mengembalikan kuesioner menurut batas waktu yang telah ditentukan. Satu kuesioner tidak dapat diolah akibat tidak lengkap sehingga usable rate dari kuesioner tersebut adalah $85 \%$.

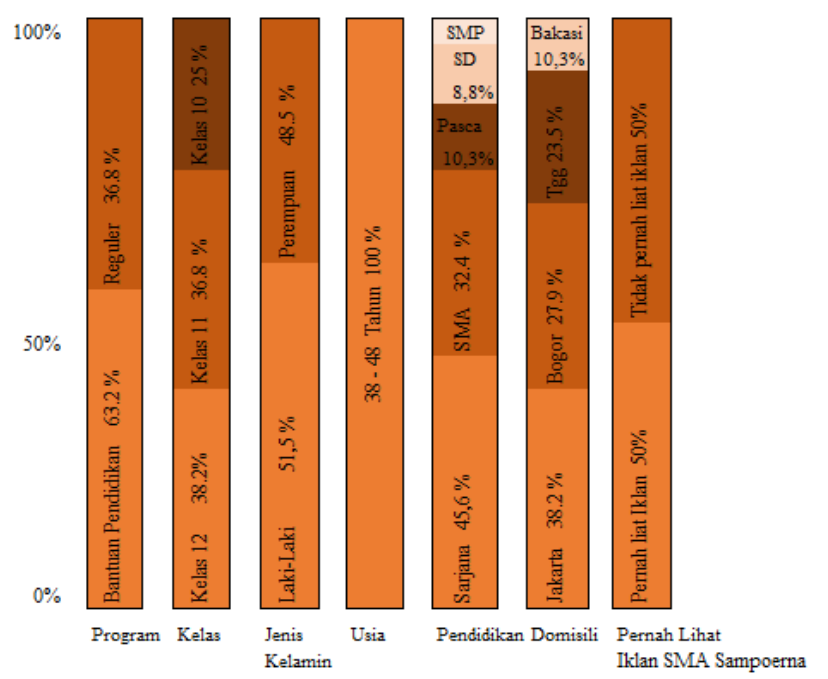

Gambar 2. Profil responden secara keseluruhan

Mayoritas orangtua yang menjadi responden pada penelitian ini adalah orang tua yang memperoleh program bantuan pendidikan dan putra/putri responden tersebut mayoritas berada di kelas 12 dan 11 . Semua responden berusia 38-48 tahun dan mayoritas pendikan adalah sarjana dan tingkat SMA. Responden tersebut jika dilihat dari keterwakilan populasi dapat disimpulkan semua kota terwakili di atas $80 \%$. Hanya $50 \%$ dari total responden pernah melihat program iklan SMA Sampoerna, karena mayoritas responden adalah memperoleh program bantuan pendidikan seperti yang tersaji pada Gambar 3. 


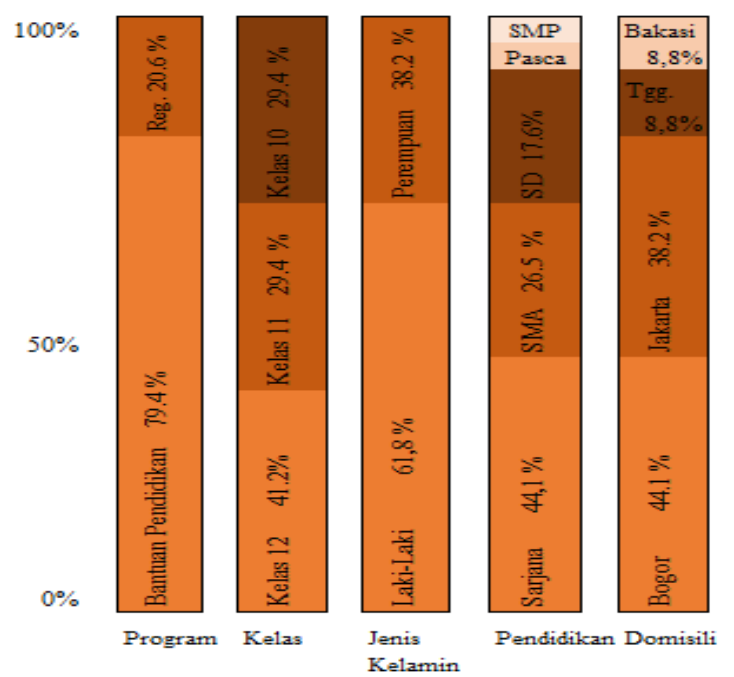

Gambar 3. Profil responden yang tidak mengetahui program iklan SMA Sampoerna

Program iklan untuk tahun 2012 lebih sedikit daripada tahun 2013, maka wajar jika mayoritas responden yang tidak mengetahui program iklan tersebut adalah orang tua yang berasal dari angkatan tahun 2012. Selain itu, pada tahun 2013 program iklan SMA Sampoerna sangat besar, namun program iklan tersebut tidak diketahui oleh orang tua siswa. Hal ini disebabkan karena 80\% responden memperoleh program bantuan pendidikan yang bukan merupakan target pasar program iklan SMA Sampoerna.

Pada Gambar 4 ditampilkan dan di analisis profil responden yang mengetahui program iklan SMA Sampoerna. Dari responden tersebut diidentifikasi di media apa saja program iklan SMA Sampoerna pernah di dengar atau di baca dan berapa banyak frekuensi mendengar atau membaca program iklan tersebut.

Berdasarkan Gambar 4, 52,9\% orang tua mengetahui, atau pernah melihat program iklan SMA Sampoerna adalah orang tua yang mengambil program reguler. Putra/putri para responden mayoritas berada di kelas 11. Perbedaan jumlah responden perempuan dan laki-laki tidak nyata. Pendidikan terakhir responden yang pernah melihat program iklan SMA Sampoerna adalah mayoritas sarjana dan SMA. Responden yang pernah melihat program iklan SMA Sampoerna mewakili $50 \%$ dari populasi responden yang berdomisili di Jakarta, $81 \%$ dari populasi responden yang berdomisili di Tangerang, 21\% dari jumlah populasi responden yang berlokasi di Bogor dan $57 \%$ dari populasi responden yang berdomisili di Bekasi. Sebanyak 44,1\% responden pernah melihat program iklan SMA Sampoerna di koran, $17,6 \%$ respoden pernah mendengar program iklan SMA Sampoerna pada radio talkshow dan 29,4\% pernah mengetahui program iklan SMA Sampoerna dikedua program iklan tersebut.

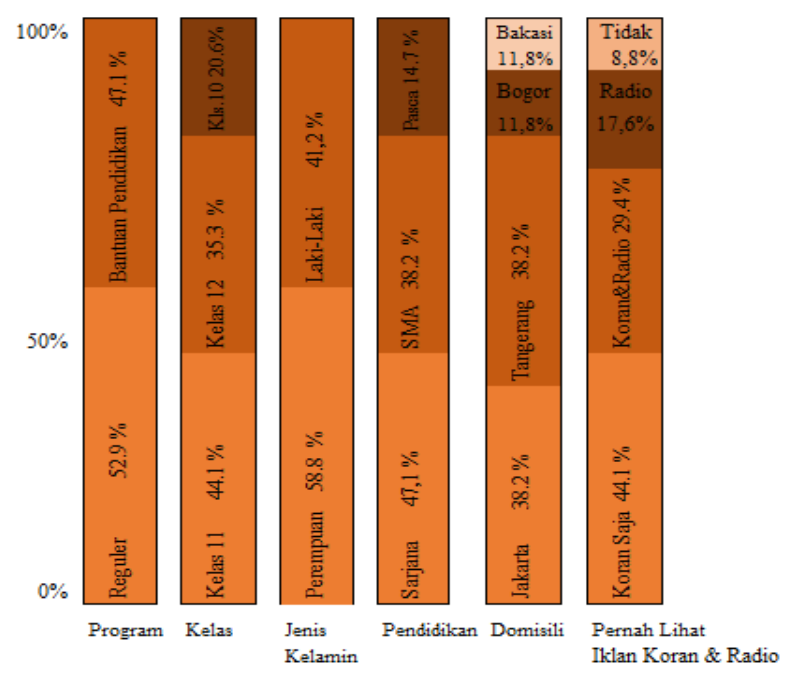

Gambar 4. Profil responden yang mengetahui program iklan SMA Sampoerna

Berdasarkan urutan, program radio talkshow paling banyak didengar di radio Cosmopolitan FM, Sindo FM dan Pas FM dengan banyaknya frekuensi mendengar mayoritas satu kali. Pada iklan cetak, berdasarkan urutan, responden paling banyak mengetahui iklan SMA Sampoerna melalui Koran Kompas dan Koran Sindo dengan frekuensi membaca iklan satu dan dua kali. Responden pertama kali mengetahui SMA Sampoerna melalui program iklan di media elektronik dan media cetak (32\%), informasi teman/kerabat (29\%) dan sisanya sebanyak $6 \%$ melalui iklan media luar ruangan.

\section{Hasil Uji Validitas dan Realibilitas}

Berdasarkan hasil perhitungan dengan menggunakan SmartPLS, indikator-indikator dalam setiap peubah tersebut memiliki nilai $r$ hitung $0,613-0,945$ atau $>r$ tabel $(0,349)$. Hal ini menunjukkan bahwa semua indikator dalam setiap peubah tersebut valid. Uji reliabilitas digunakan untuk mengetahui suatu hasil pengukuran relatif konsisten. Berdasarkan hasil perhitungan, didapatkan nilai cronbach alpha 0,968 atau lebih besar dari 0,7. Hal ini menunjukan semua indikator pada setiap peubah tersebut sudah reliabel/ konsisten.

\section{Hasil Evaluasi Model Outer}

Model Outer dinilai dengan cara melihat convergent validity (besarnya loading factor untuk 
masing-masing konstruk). Selain itu, model outer juga dapat dinilai dengan menggunakan nilai composit realiability dan cronbach alpha. Selain melihat convergent validity, model outer juga dinilai dengan cara melihat dicriminant validity yaitu cross loading pengukuran dengan konstruk.

\section{Hasil Uji Reliabilitas Peubah Penelitian}

Konsistensi pengukuran (reliabilitas) da-pat diuji dengan Average Variance Extract (AVE) dan Composite Realiability (CR). Berdasarkan hasil perhitungan dengan menggunakan SmartPLS, peubah/konstruk laten brand awareness, efektifitas iklan, endorser, media Iklan dan pesan Iklan memiliki nilai composite reliability $\left(\mathrm{Qc}_{\mathrm{c}}\right)>0,8$ yang berarti indikator-indikator yang merefleksikan konstruk laten tersebut memiliki konsistensi tinggi dalam mengukur konstruk latennya. Dari tabel di bawah juga diketahui bahwa masingmasing konstruk reliabel memiliki nilai nilai cronbach alpha (@c) $>0,8$. Selain itu semua peubah/konstruk memiliki nilai $A V E$ hasil penelitian $>0,5$. Hal ini menjelaskan bahwa semua indikator-indikator tersebut mempunyai konsistensi tinggi dalam mengukur konstruk/peubah latennya.

Tabel 2. Nilai reliabilitas komposit, cronbachs alpha dan AVE

\begin{tabular}{l|c|c|c}
\hline Peubah & $\begin{array}{c}\text { Nilai } \\
\text { CR }\end{array}$ & $\begin{array}{c}\text { Nilai } \\
\text { Cronbachs } \\
\text { Alpha }\end{array}$ & $\begin{array}{c}\text { Nilai } \\
\text { AVE }\end{array}$ \\
\hline Brand awareness & 0,909366 & 0,866795 & 0,715268 \\
Efektivitas iklan & 0,958271 & 0,945377 & 0,821341 \\
Endorser & 0,898124 & 0,829636 & 0,746533 \\
Media iklan & 0,949851 & 0,929446 & 0,825768 \\
Pesan iklan & 0,932004 & 0,901640 & 0,774822 \\
\hline
\end{tabular}

\section{Nilai Outer Loadings Indikator Penelitian}

Berdasarkan perhitungan dengan menggunakan SmartPLS diketahui bahwa sebagian besar nilai loading outernya $>0,7$. Hal ini menunjukan bahwa indikator mampu merefleksikan peubah secara konsisten dan stabil. Konstruk endorser dapat direfleksikan oleh adanya kecocokan endorser dengan khalayak $\left(\mathrm{G}_{1}\right)$ dan merek $\left(G_{2}\right)$ daya tarik endorser $\left(G_{3}\right)$ dan kredibilitas endorser. Simbol jaminan standar $\left(\mathrm{G}_{4}\right)$ tidak dapat merefleksikan kredibilitas endorser. Dalam kasus SMA Sampoerna logo/gambar CIE kurang mendorong program iklan tersebut, dan logo tersebut tidak familiar bagi khalayak yang belum mengetahui pendidikan berstandar internasional.
Pesan iklan yang baik direfleksikan dengan pesan iklan tersebut menarik perhatian (attention) $\left(\mathrm{H}_{5}\right)$, menarik minat (interest) $\left(\mathrm{H}_{6}\right)$, membangkitkan keinginan (desire) $\left(\mathrm{H}_{7}\right)$ dan menyebabkan tindakan (action) $\left(\mathrm{H}_{8}\right)$. Konstruk pemilihan media iklan direfleksikan oleh mutu dari siaran yang dihasilkan (I9), penjadwalan iklan ( $\left.\mathrm{I}_{11}\right)$, jangkauan media ( $\left.\mathrm{I}_{12}\right)$ dan frekuensi iklan $\left(\mathrm{I}_{13}\right)$. Pemilihan media iklan tidak dapat direfleksikan atau tidak berkorelasi dengan indi-kator popularitas media $\left(\mathrm{I}_{10}\right)$. Dalam pemilihan media, tidak harus media itu populer di mata khalayak melainkan media tersebut untuk menyampaikan program/pesan iklan kepada khalayak menurut target yang diinginkan.

Konstruk efektifitas iklan direfleksikan oleh indikator-indikator: merek yang dikenal dan diingat oleh khalayak ( $\left.\mathrm{J}_{14}\right)$, khalayak memahami keunggulan produk (J15) dan memiliki kepercayaan terhadap produk (J16), memengaruhi pembelian/penggunaan produk tersebut ( $\left.\mathrm{J}_{18}\right)$ dan menimbulkan citra yang positif terhadap produk $\left(\mathrm{J}_{19}\right)$. Indikator khalayak meyakini bahwa produk lebih baik tidak dapat merefleksikan konstruk efektifitas iklan. Konstruk brand awareness direfleksikan dengan baik oleh indikator ketidaksadaran terhadap merek (unaware of brand) $\left(\mathrm{K}_{20}\right)$, pengenalan merek (brand recognition) $\left(\mathrm{K}_{21}\right)$, ingat terhadap merek (brand recall) $\left(\mathrm{K}_{22}\right)$ dan merek menjadi pilihan utama (top of mind) $\left(\mathrm{K}_{23}\right)$.

\section{Hasil Analisis Korelasi Antar Peubah Laten dan Akar AVE}

Discriminat validity dari model pengukur-an dengan indikator reflektif dinilai berdasarkan cross loading pengukuran dengan konstruk. Cara lain mengukur discriminat validity adalah melihat nilai square root of average variance extracted (AVE). Berdasarkan perhitungan dengan SmartPLS diketahui bahwa nilai sebagian besar square root of average variance extracted > dibandingkan dengan nilai korelasi antar konstruk lainnya. Hal ini mengindikasikan konstruk brand awareness, efektivitas iklan, endorser, pesan iklan dan media iklan memiliki validitas diskriminan yang tinggi.

\section{Hasil Analisis Cross Loadings Indikator}

Berdasarkan perhitungan dengan SmartPLS, diketahui semua korelasi indikator ke peubah laten lebih besar dari korelasi ke-peubah laten lainnya, sehingga validitas terpenuhi sesuai syarat indikator mempunyai korelasi ke peubah laten sendiri lebih besar dari peubah laten lainnya. 
Pada Gambar 4 dimuat output PLS alogaritm awal. Indikator $\mathrm{G}_{4}$ (simbol jaminan standar) tidak berkorelasi terhadap konstruk endorser, indikator $\mathrm{I}_{10}$ (popularitas media) tidak berkorelasi dengan konstruk media iklan, indikator $\mathrm{J}_{17}$ (khalayak meyakini bahwa produk lebih baik) tidak berkorelasi dengan konstruk efektifitas iklan, sehingga ketiga indikator tersebut di eliminasi dalam model. Selanjutnya, konstruk brand awareness direfleksikan oleh empat buah indikator $\left(\mathrm{K}_{20}-\mathrm{K}_{23}\right)$ dan semua indikator tersebut berkorelasi dengan konstruk brand awareness.

\section{Hasil Evaluasi Model Inner}

Untuk menilai inner model adalah dengan melihat hubungan antara peubah/konstruk laten, melihat hasil estimasi koefisien parameter jalur dan tingkat signifikansinya (Tabel 3).

\section{Hubungan Antar Konstruk Endogen Brand Awareness dan Efektifitas Iklan}

Hasil $R$-square sebesar 0,67; 0,33 dan 0,19 untuk peubah laten endogen (peubah dependen) dalam model struktural mengindikasikan model tersebut baik moderat dan lemah. Nilai $\mathrm{R}^{2}$ untuk peubah brand awareness 0,887 (termasuk pada penggolongan baik), menunjukan bahwa variabilitas brand awareness yang dapat dijelaskan oleh konstruk efektivitas, endorser, media iklan dan pesan iklan adalah $88 \%$. Peubah efektivitas iklan memiliki nilai $\mathrm{R}^{2}$ sebesar 0,800 (termasuk penggolongan baik). Hal ini menunjukan peubah efektivitas dapat dapat dijelaskan $80 \%$ oleh konstruk endorser, media iklan dan pesan iklan dan $20 \%$ lainnya dijelaskan oleh peubah diluar konstruk.

\section{Hasil Analisis Koefisien Jalur Struktural}

Hubungan konstruk eksogen dan konstruk endogen dapat dilihat dengan uji $t$ statistik dan koefisien jalur struktural. Apabila nilai $t$ statistik > $\mathrm{t}$ tabel, maka konstruk endogen berpengaruh terhadap konstruk eksogen. Perhitungan uji $t$ dengan rumus berikut:

$$
t=\frac{\left(\rho_{i k}-\rho_{j k}\right)}{\sqrt{\left(1-R_{k(1,2,3, . . k)}^{2}\right)\left(c_{i i}+c_{j i}-2 c_{j j}\right)}}
$$

Hasil bootstraping yang terdapat pada Tabel 2 menjelaskan terdapat pengaruh sangat nyata efektivitas iklan terhadap brand awareness, media iklan terhadap brand awareness dan pesan iklan terhadap efektivitas iklan dengan nilai pvalue $<0,05$ atau nilai thitung $>$ tabel $(1,96)$.

Dalam penelitian ini brand awareness diukur dengan empat konstruk eksogen, yaitu efektivitas iklan, endorser, pesan iklan dan media iklan. Berdasarkan hasil pengolahan data dengan SmartPLS, konstruk efektifitas iklan dengan nilai $\mathrm{t}$ statistik 3,959988 dan konstruk media iklan dengan nilai $\mathrm{t}$ statistik 2,346884 ( $>\mathrm{t}$ tabel), berpengaruh nyata terhadap endogennya yaitu brand awareness dan konstruk endorser ( $t$ statistik 0,035700) dan pesan iklan (t statistic 0,167740) tidak berpengaruh nyata langsung terhadap brand

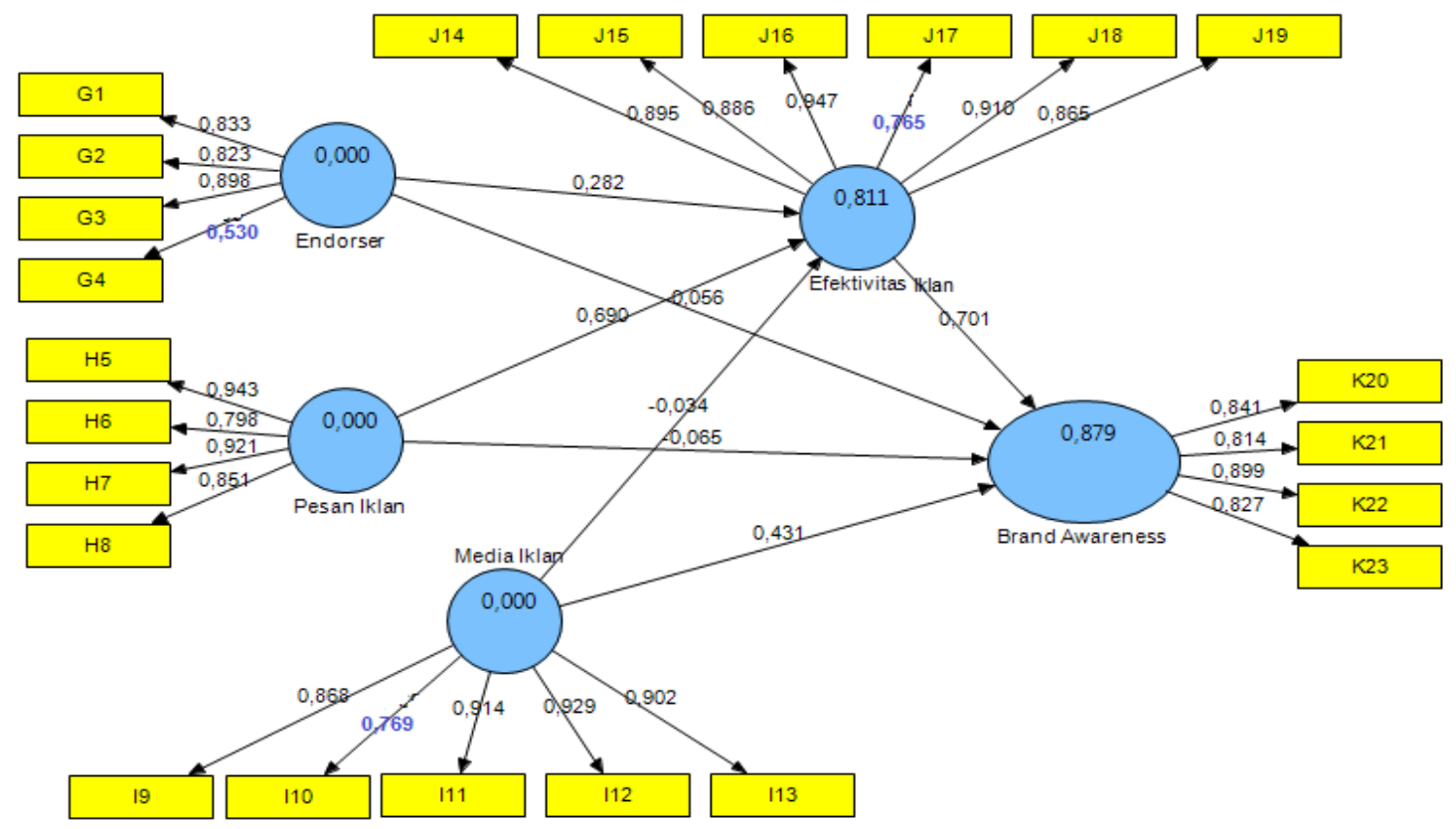

Gambar 4. Hasil output model awal penelitian 
Tabel 3. Tabel nyata inner model

\begin{tabular}{lccccc}
\hline & $\begin{array}{c}\text { Original } \\
\text { Sample }\end{array}$ & $\begin{array}{c}\text { Sample } \\
\text { Mean }\end{array}$ & $\begin{array}{c}\text { Standard } \\
\text { Deviation }\end{array}$ & $\begin{array}{c}\text { Standard } \\
\text { Error }\end{array}$ & $\begin{array}{c}\text { t statistic } \\
\left({ }^{*} \mathrm{p}<0,05\right)\end{array}$ \\
\hline Efektivitas Iklan $\rightarrow$ Brand Awareness & 0,650350 & 0,659578 & 0,164230 & 0,164230 & 3,959988 \\
Endorser $\rightarrow$ Brand Awareness & $-0,006075$ & 0,001312 & 0,170180 & 0,170180 & 0,035700 \\
Pesan Iklan $\rightarrow$ Brand Awareness & $-0,023080$ & $-0,013775$ & 0,137595 & 0,137595 & 0,167740 \\
Media Iklan $\rightarrow$ Brand Awareness & 0,385917 & 0,362667 & 0,164438 & 0,164438 & 2,346884 \\
Endorser $\rightarrow$ Efektivitas Iklan & 0,185083 & 0,178602 & 0,151263 & 0,151263 & 1,223584 \\
Pesan Iklan $\rightarrow$ Efektivitas Iklan & 0,651739 & 0,638641 & 0,172584 & 0,172584 & 3,776358 \\
Media Iklan $\rightarrow$ Efektivitas Iklan & 0,111759 & 0,131516 & 0,202388 & 0,202388 & 0,552201 \\
\hline
\end{tabular}

awareness, karena ( $\mathrm{t}$ hitung $<\mathrm{t}$ tabel). Hasil penelitian ini sejalan dengan penelitian Puspitasari (2009) yang menyatakan efektifitas iklan berpengaruh pada peningkatan brand awareness, untuk meningkatkan brand awareness SMA Sampoerna di mata khalayak, haruslah iklan yang ditampilkan tersebut mudah dingat, baik iklan itu sendiri dan merek yang diiklankan, iklan tersebut dapat dengan mudah dipahami dan mampu menggambarkan keunggulan produk, sehingga khalayak memiliki kepercayaan positif terhadap produk tersebut.

Konstruk media iklan berpengaruh nyata langsung terhadap peningkatan brand awareness, sehingga terdapat alternatif lainnya untuk mempercepat peningkatan brand awareness SMA Sampoerna dengan melakukan pemilihan media periklanan yang tepat. Berdasakan diskusi mendalam dengan beberapa responden terdapat tiga hal yang harus ditingkatkan dalam kampanye periklanan SMA Sampeorna yang berkaitan dengan pemilihan media periklanan, yaitu program iklan SMA Sampoerna harus lebih ditingkatkan frekuensi tayangnya di media yang dipilih, durasi iklan khususnya program radio talkshow harus ditambah dan menggunakan media iklan yang memiliki jangkauan lebih luas. Hasil penelitian ini dapat bermanfaat bagi manajemen SMA Sampoerna, karena mengevaluasi program iklan dan menemukan alternatif untuk meningkatkan brand awareness SMA Sampoerna. Konstruk endorser dan pesan iklan tidak berpengaruh nyata secara langsung terhadap brand awareness. Sesuai dengan model awal penelitian yang dibangun berdasarkan penelitian terdahulu, bahwa pengaruh endorser dan daya tarik pesan iklan diduga memiliki hubungan nyata dengan efektifitas iklan bukan dengan peningkatan brand awareness. Pada Gambar 5, terlihat lebih jelas pengaruh negatif konstruk endorser dan pesan iklan terhadap brand awareness.

Hasil riset Macdonald dan Sharp (2003) terhadap middle manager di Australia menemukan bahwa banyak manager tidak memperhatikan pentingnya brand awareness dan kurang adanya pengukuran dan pemeliharaan secara terus menerus terhadap brand awareness. Mayoritas perusahaan memandang bahwa keberhasilan pemasaran lebih diukur dengan keberhasilan penjualan produk/jasa pada saat itu, tanpa mempertimbangkan hubungan pelanggan jangka panjang dan keberhasilan penjualan dimasa yang akan datang. Pada kasus SMA Sampoerna, diperlukan pemeliharaan terhadap brand awareness yang terbentuk oleh program iklan yang efektif, sehingga brand tersebut dapat terus diingat dalam puncak pikiran khalayak.

Pada penelitian ini efektivitas program iklan diukur dengan menggunakan tiga konstruk eksogen, yaitu endorser, pesan iklan dan media iklan. Berdasarkan hasil pengolahan data menggunakan SmartPLS, konstruk pesan iklan memiliki nilai $\mathrm{t}$ statistik 3,776358 ( $>\mathrm{t}$ tabel), sehingga berpengaruh nyata terhadap efektifitas iklan. Hal ini sejalan dengan penelitian Riyanto (2008) yang menyatakan bahwa pesan iklan yang menarik meningkatkan efektifitas program iklan tersebut.

Ada beberapa hal yang disampaikan oleh responden untuk meningkatkan daya tarik pesan iklan dari segi khalayak umum, yaitu dari segi tampilan iklan harus dibuat lebih menarik, jika diperlukan menggunakan ilustrasi dan warna yang lebih baik dan lebih tampilan modern (tidak korporat). Iklan koran, khususnya menggunakan bahasa yang lebih mudah dipahami dan menitikberatkan pada informasi pada program dan fasilitas yang ditawarkan, namun harus tetap sesuai dengan kenyataan yang ada. 


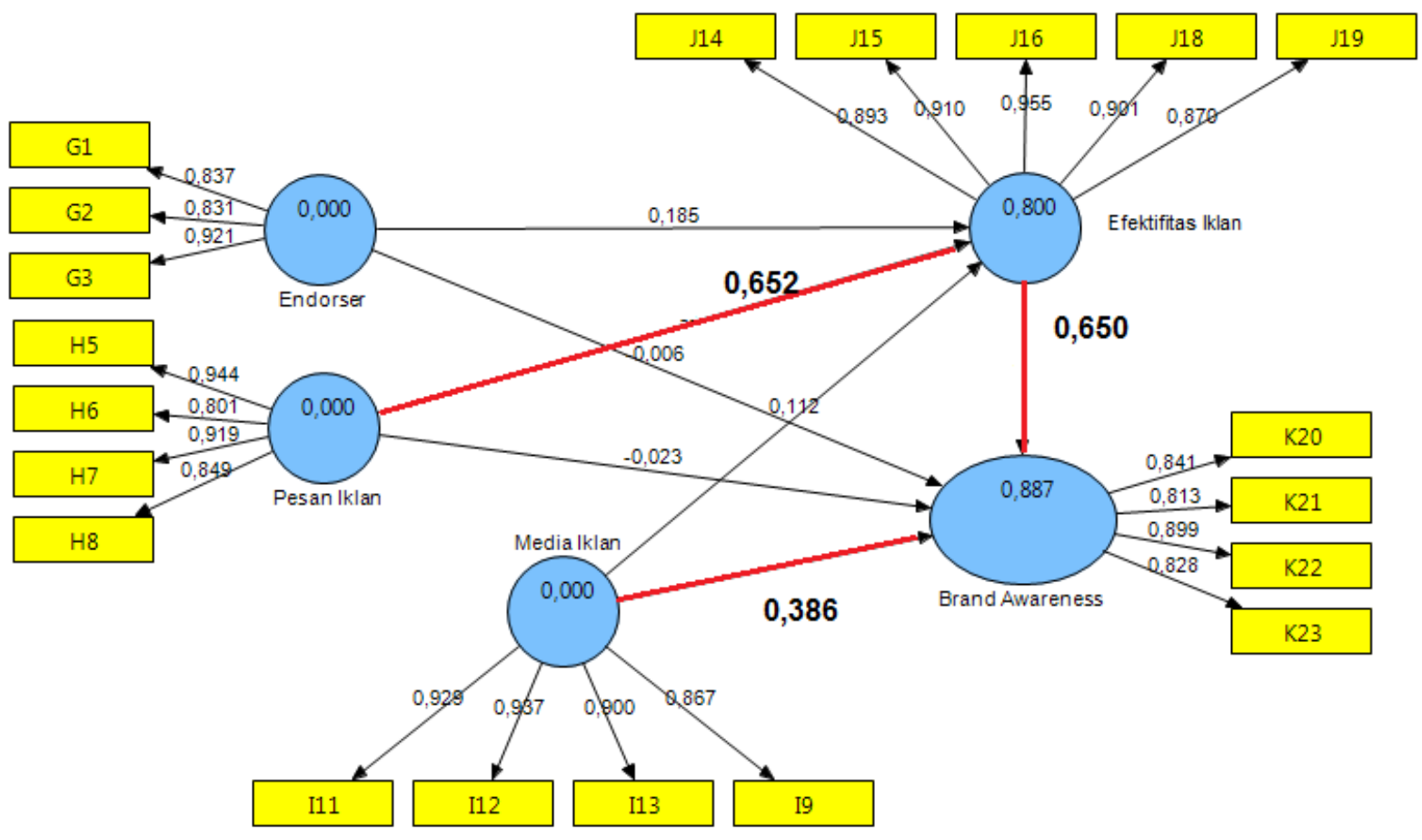

Gambar 5. Hasil model akhir penelitian

Konstruk endorser memiliki nilai $\mathrm{t}$ statistik 1,223584 ( $<\mathrm{t}$ tabel) dan konstruk media iklan memiliki nilai $\mathrm{t}$ statistik 0,552201 $(<\mathrm{t}$ tabel $)$, sehingga tidak memiliki pengaruh nyata terhadap konstruk endogennya, yaitu efektivitas iklan. Endorser tidak berpengaruh nyata terhadap efektifitas iklan dikarenakan produk pendidikan di Indonesia, dimana khalayak belum sepenuhnya percaya terhadap dukungan para endorser, sedangkan pemilihan media dianggap tidak berpengaruh signifikan terhadap efektifitas iklan, melainkan berpengaruh nyata terhadap brand awareness. Maka pemilihan media menjadi sangat penting, khususnya dalam hal penjadwalan dan jangkauan yang dimiliki oleh media yang dipilih. Franses dan Vriens (2004) mengatakan bahwa media yang berbeda seperti televisi, radio dan majalah digunakan dan dikonsumsi secara berbeda. Media-media tersebut memiliki dampak jangka pendek yang berbeda-beda. Beriklan pada waktu yang berbeda akan juga menyebabkan dampak yang berbeda pula.

Uji hubungan konstruk menunjukan bahwa semua konstruk berpengaruh dengan nilai koefisien parameter 0,00-0,65. Pengaruh nyata terdapat pada hubungan efektivitas iklan dengan brand awareness, media iklan terhadap brand awareness dan daya tarik pesan iklan terhadap efektifitas iklan.

Pemilihan media periklanan menjadi sangat penting bagi keberhasilan strategi pemasaran
SMA Sampoerna dan hal ini sejalan dengan Supratini (2006) yang mengungkapkan pemilihan media iklan yang tepat akan menentukan berhasil tidaknya strategi pemasaran dan penjualan. Hal tersebut sejalan dengan Reviani dan Indriani (2011), bahwa iklan efektif adalah alat pemasaran yang penting dalam membantu meningkatkan kesadaran konsumen akan brand. Pengaruh tidak nyata dan positif adalah endorser terhadap efektivitas iklan dan media iklan terhadap efektivitas iklan.

Pengaruh negatif terdapat pada hubung-an antara endorser terhadap brand awareness dan hubungan antara pesan iklan terhadap brand awareness. Pengaruh negatif pada hubungan endorser dengan brand awareness dapat dimengerti, karena produk pendidikan berbeda dengan produk konsumsi yang semakin baik/kredibel endorsernya dapat meningkatkan brand awareness di mata khalayak (Bachriansyah, 2011).

Berdasarkan hasil penelitian ini perlu manajemen SMA Sampoerna memperhatikan efektifitas program iklan yang dilakukan. Iklan yang nanti akan dibuat haruslah mudah dingat, dapat dengan mudah dipahami dan mampu menggambarkan kenggulan produk sehingga khalayak memiliki kepercayaan positif terhadap produk tersebut, selain itu manajemen SMA Sampoerna tidak lagi menggunakan siswa-siswi SMA Sampoerna sebagai endorser pada program iklan di radio talkshow maupun iklan koran 
karena penggunaan siswa-siswi tersebut tidak memberikan pengaruh terhadap efektifitas iklan SMA Sampoerna. sebagai alternatif pengganti endorsernya adalah dengan menampilkan sosok alumni SMA Sampoerna sebagai endorser.

Terhadap media periklanan yang nanti-nya akan dipilih perlu memperhatikan hal berikut: (1) meningkatkan frekuensi tayang iklan di media yang dipilih, (2) menambah durasi iklan khususnya program pada radiotalkshow, dan (3) memilih media iklan yang memiliki jangkauan yang luas.

\section{Hasil Uji Hipotesis}

Berdasarkan evaluasi model outer (uji t dan koefisien jalur struktural) yang terlah dikembangkan tersebut, didapatkan kesimpulan terhadap hipotesis yang diajukan pada awal penelitian. Kesimpulan uji hipotesis tersebut sebagai berikut:

1. Hipotesis pertama: Mutu endorser berpengaruh pada efektifitas iklan $\rightarrow$ Hipotesis ditolak

2. Hipotesis kedua: Daya tarik pesan iklan berpengaruh pada efektifitas iklan $\rightarrow$ Hipotesis diterima

3. Hipotesis ketiga: Ketepatan pemilihan media iklan berpengaruh pada efektifitas iklan $\rightarrow$ Hipotesis ditolak

4. Hipotesis keempat: Efektifitas iklan berpengaruh terhadap brand awareness produk $\rightarrow$ Hipotesis diterima.

Hipotesis 1 dan 3 ditolak, hal ini menjelaskan bahwa kedua hipotesis pada model pada penelitian SMA Sampoerna (seperti tersaji pada Gambar 6 di atas) tidak relevan. Garis merah pada Gambar 6 di atas adalah jalur yang dihasilkan dalam penelitian ini yang bisa jadi berbeda dengan penelitian lain dengan model yang sama apabila model ini direplikasi dengan subyek penelitian (sekolah berasrama) yang berbeda.

\section{KESIMPULAN}

1. Mutu endorser berpengaruh tidak nyata terhadap efektifitas iklan SMA Sampoerna. Hal ini disebakan khalayak belum sepenuhnya percaya terhadap dukungan endorser dan mutu endorser berpengaruh negatif terhadap peningkatan brand awareness SMA Sampeorna.

2. Daya tarik pesan iklan berpengaruh nyata terhadap efektifitas iklan, maka desain pesan iklan dan isi pesan iklan haruslah dibuat semenarik mungkin bagi khalayak, namun tetap memuat kenyataan di lapangan. Selain itu, pengaruh negatif terdapat pada hubungan pesan iklan terhadap peningkatan brand awareness SMA Sampoerna.

3. Ketepatan pemilihan media iklan berpengaruh tidak nyata terhadap efektifitas iklan, namun ketepatan pemilihan media iklan berpengaruh nyata terhadap peningkatan brand awareness SMA Sampoerna. Maka pemilihan media menjadi sangat penting, khususnya dalam hal penjadwalan dan jangkauan yang dimiliki oleh media terpilih.

4. Efektifitas iklan berpengaruh nyata terhadap peningkatan brand awareness SMA Sampoerna.

\section{DAFTAR PUSTAKA}

Bachriansyah, Rizky A. 2011. Analisis Pengaruh Kualitas Produk, Daya Tarik Iklan, Dan Persepsi Harga Terhadap Minat Beli Konsumen Pada Produk Ponsel Nokia (Studi Kasus Pada Masyarakat di Kota Semarang). [jurnal] Semarang (ID): Jurnal Universitas Diponegoro Hal. 1-30. [internet].[diunduh pada 14 May 2014]. Tersedia pada: http://eprints.undip.ac.id.

[Dikti] Direktorat Jenderal Pendidikan Tinggi, Kementrian Pendidikan Dan Kebudayaan. 2010. Peraturan Pemerintah Nomer 17 Tahun 2010 tentang Pengelollan dan Penyelenggaran Pendidikan di Indonesia. [internet].[diunduh pada 3 April 2014]. Tersedia pada: http://www.dikti.go.id/id/peraturanperundangan/.

Fransen, Philip Hans dan Vriens, Marco. 2004. Advertising Effects on Awareness, Consideration and Brand Choise Using Traccking Data. [jurnal] Rotterdam (NED): Publication of Erasmus Reaseach Institute of Management (ERS-2004-028MKT) Hal 119. [internet].[diunduh pada 9 May 2014]. Tersedia pada: http://erim.eur.nl.

Kotler P, Keller K. 2009. Manajemen Pemasaran Jilid 1. Jakarta (ID): Erlangga

Kotler P, Lee N.R. 2009. Up and Out of Poverty. The Social Marketing Solution. New Jersey (USA): Wharton School Publishing

Lamb C, Hair J, Mc Daniel C. 2001. Pemasaran Buku 2. Jakarta (ID): Salemba Empat.

Macdonald E, Sharp B. 2003. Management Perceptions of the Importance of Brand Awareness as an Indication of Advertising 
Effectiveness. [jurnal] (AUS): Marketing Bulletin University of South Australia Vol. 14, Hal. 1-14[internet].[diunduh pada 9 May 2014]. Tersedia pada: http://marketingbulletin.massey.ac.nz.

[Nielsen] AC Nielsen. 2012.Survey Market Potensial Sampoerna Academy. Jakarta (ID): Nielsen Pr.

[PSF] Putera Sampoerna Foundation. 2014. Pengeluaran Iklan SMA Sampoerna Periode Januari 2012-Maret 2014. PSF Pr, Jakarta (ID).

Puspitasari, Intan. 2009. Faktor-Faktor Yang Memengaruhi Efektifitas Iklan Dalam Menumbuhkan Brand Awareness, Studi Pada Program Periklanan Telkom Flexi Pada Mahasiswa Universitas Diponegoro Semarang [tesis]. Universitas Diponegoro, Semarang (ID).

Rangkuti, F. 2002. The Power of Brand. Gramedia Pustaka Utama, Jakarta (ID).

Raviani AHS, Indriani, F. 2011. Analisis Pengaruh Efektifitas Iklan Pesaing Dan Perilaku Mencari Variasi Terhadap Perilaku Penpindahan Merek Pada Konsumen Teh Botol Sosro. [jurnal] Semarang (ID): Jurnal Universitas Diponegoro Hal. 1-28. [internet]. ].[diunduh pada 14 May 2014] Tersedia pada: http://eprints.undip.ac.id/ 28654/1/jurnal.pdf.
Riyanto, Makmun. 2008. Analisis Faktor Yang Memengaruhi Efektifitas Iklan Dan Implikasinya Terhadap Sikap Merek, Studi Kasus Pada Iklan Ponds Di Kota Semarang [tesis]. Universitas Diponegoro, Semarang (ID).

Sasetyo, Septa Adi. 2012. Pengaruh Daya Tarik Iklan Terhadap Pembentukan Citra Merek Pepsodent.[jurnal] Bandung (ID): Jurnal Mahasiswa Universitas Padjajaran Vol. 1,Hal 1-19. [internet]. [diunduh pada 14 May 2014]. Tersedia pada: http://journals. unpad. ac.id.

Sumarwan, Ujang. 2011. Perilaku Konsumen Teori Dan Penerapannya. Ghalia Indonesia, Bogor (ID):

Supraptini, Nunuk. 2006. Memilih Media Iklan Yang Tepat. [jurnal] Semarang (ID): Jurnal Inkoma Vol. 1, Hal. 34-40 Undaris Ungaran. [internet]. [diunduh pada 14 May 2014]. Tersedia pada: http://jurnal.undaris.ac.id/ index.php/ekonomi/article/view/49

[UM] Curious Mind. 2012. ADEX For Internatioal School. Jakarta (ID): Curious Mind Pr.

Umar, Husein. 2003. Metode Riset Perilaku Konsumen Jasa. Ghalia Indonesia, Jakarta (ID). 